\title{
Abyssinone V-4' Methyl Ether Isolated from Erythrina droogmansiana (Leguminosae) Inhibits Cell Growth and Mammary Glands Hyperplasia Induced in Swiss Mice by the 7,12-Dimethylbenz(a)anthracene
}

\author{
Alain Brice Tueche, ${ }^{1}$ Stephane Zingue $\left(\mathbb{D},{ }^{2}\right.$ Edwige Nana Tchoupang, ${ }^{3}$ \\ Telesphore Nanbo Gueyo, ${ }^{3}$ Abel Joël Gbaweng Yaya, ${ }^{4}$ Amstrong Nang Njuh, ${ }^{1}$ \\ Dieudonnée Mireille Ntsa, ${ }^{3}$ and Dieudonné Njamen $\mathbb{D D}^{3}$ \\ ${ }^{1}$ Department of Biological Sciences, Faculty of Science, University of Maroua, P.O. Box 814, Maroua, Cameroon \\ ${ }^{2}$ Department of Life and Earth Sciences, Higher Teachers' Training College, University of Maroua, P.O. Box 55, Maroua, Cameroon \\ ${ }^{3}$ Department of Animal Biology and Physiology, Faculty of Science, University of Yaoundé 1, P.O. Box 812, Yaounde, Cameroon \\ ${ }^{4}$ Centre for Research on Medicinal Plants and Traditional Medicine, Institute of Medical Research and Medicinal Plants Studies, \\ Yaounde, Cameroon \\ Correspondence should be addressed to Stephane Zingue; stephanezingue@gmail.com
}

Received 17 April 2018; Revised 12 June 2018; Accepted 24 June 2018; Published 11 July 2018

Academic Editor: Robert Kubina

Copyright (C) 2018 Alain Brice Tueche et al. This is an open access article distributed under the Creative Commons Attribution License, which permits unrestricted use, distribution, and reproduction in any medium, provided the original work is properly cited.

\begin{abstract}
There is a long standing interest in the identification of medicinal plants and derived natural products for developing cancer therapeutics. The present study was designed to evaluate the in vitro and in vivo antiproliferative effects of Abyssinone V-4' methyl ether (AVME) on breast tissue of mice. The cytotoxicity of AVME was evaluated using MTT assay in four cancer cell lines (DU145, PC3, HepG2, and MCF-7). Further, a protective effect of AVME was evaluated on 7,12-dimethylbenz(a)anthracene- (DMBA-) induced breast tumor in Swiss mice. Incidence, burden, volume, and histological analysis of mammary tumors were measured. As a result, AVME inhibits DU145, PC3, HepG2, and MCF-7 cells growth. In vivo, no tumor was detected in mice from the normal group as compared to those of DMBA group. Moreover, AVME inhibits the DMBA-induced mammary glands hyperplasia in mice at the dose of $10 \mathrm{mg} / \mathrm{kg}$, evidenced by a decrease of tumor incidence, tumor weight, and volume as well as a protective effect against the lobular alveolar hyperplasia. Taken all together, these results suggest that Abyssinone V-4' methyl ether is endowed with antitumor properties and could be a source of traditional medicine which deserves to be more elucidated and explored in the foreseeable future.
\end{abstract}

\section{Introduction}

Cancer is a heterogenous condition where normal cells take up a malignant phenotype, proliferating indefinitely and uncontrollably, thereby leading to a destruction of the original tissue [1] and later advances in a multistep process with various hallmarks including rapid proliferation, resisting cell death, neoangiogenesis, local invasion, and remote metastasis [2]. It is an important cause of death worldwide, posing a major threat to public health. More than 1.1 million people are diagnosed of cancer each year; among them almost 410,000 deaths are registered. According to Plummer et al. [3], over 8 million deaths can be linked with cancer. The World Health Organization (WHO) fears that, by 2030, cancer deaths may increase by up to $50 \%$, thereby reaching about 15.000 .000 . There are many types of cancers, among which breast cancer is the leading cause of death in women with 50,000 new cases per year [4]. In Cameroon, according to the Globocan estimation, among women, breast cancer is the most common before the cervical cancer with 27.9 per 100,000 cases [1] 
TABLE 1: General information on Abyssinone V-4'-methyl ether isolated from Erythrina droogmansiana.

Chemical names
$\begin{aligned} & \text { Abyssinone V-4' methyl ether } \\ & \text { 4H-1-benzopyran-4-one, } \\ & \text { 2,3-dihydro-5,7-dihydroxy-2-[4-methoxy-3,5-bis(3- } \\ & \text { methyl-2-buten-1-yl)phenyl] }\end{aligned}$

Globally, about one million women are detected with this condition annually, resulting in over 400.000 deaths from the pathology [5]. Several factors have been correlated with breast cancer; however, estrogen-dependent cancers are the most prevalent hormone-related breast cancers with $50-80 \%$ of all breast tumors and their proportion increases with age [6].

In recent years, four main medical interventions, radiotherapy, chemotherapy, immunotherapy, and hormone therapy, constitute the frontline therapies for breast cancer, surgery for advanced stages of the disease [7, 8]. However, cancer management is plagued with many limitations. Particularly for Africa, treatment cost is high, and centers for diagnosis and management are limited. These, coupled with drug resistance and systemic toxicity of current chemotherapeutic molecules, pile up the difficulties faced using the different anticancer therapies $[9,10]$. Faced with these difficulties, the quest for new anticancer molecules which are readily available, effective, and less expensive becomes a serious issue if these problems have to be overcome. Plants which are easily exploited give hope and make up a huge variety of anticancer substances with a wide variety of bioactive compounds [11]. Among these metabolites, there are abyssinones which are prenylated flavonoids. These molecules have gained attention since they are endowed with a large range of activities such as aromatase inhibitory, antioxidant, and cytotoxic activities $[12,13]$. The aim of the present study is to bring a significant contribution to the fight against cancer, by evaluating the in vitro and in vivo antiproliferative effects of Abyssinone $\mathrm{V}$ 4' methyl ether (AVME) isolated from Erythrina droogmansiana (Leguminosae). For this to be done, the ability of AVME to inhibit cancer cells growth in vitro and to prevent a 7,12dimethylbenz(a)anthracene-induced breast tumor in female mice was evaluated.

\section{Materials and Methods}

2.1. Chemicals and Reagents. The following products were acquired from Gibco/Invitrogen (Karlsruhe, Germany): penicillin, streptomycin, fetal bovine serum, glutamax, and the 2-[4-(2-hydroxyethyl)piperazin-1-yl] ethane sulfonic acid (HEPES). The 3-(4,5-dimethylthiazol-2-yl)-2,5-diphenyltetrazolium bromide (MTT) and 7,12-dimethylbenz(a)anthracene
(DMBA) (purity $\geq 95 \%$ ) were acquired from Roche Diagnostics (Penzberg, Germany) and Sigma-Aldrich (Stanford, Germany), respectively.

\subsection{Plant Material}

2.2.1. Collection and Authentication. Root barks of Erythrina droogmansiana $\mathrm{T}$. Durand (Fabaceae) were collected in Nkomekoui-Yaounde (Centre Region of Cameroon) on 21 August 2010 at about 8:00 A.M. and identified at the Cameroon National Herbarium (CNH) (Voucher specimen $\mathrm{N}^{\circ} 4261$ / SRFK) by the botanist M. Victor Nana.

2.2.2. Preparation of the Extract. A total of $1,200 \mathrm{~g}$ of airdried and pulverized root barks of E. droogmansiana was macerated in 5 liters of ethyl acetate $99.4 \%$ for 2 days at room temperature. Then, $150 \mathrm{~g}$ (12.5\%) of crude ethyl acetate extract was obtained after filtration through a Whatman $\mathrm{n}^{\circ} 4$ filter paper and evaporation of the ethyl acetate using a rotary evaporator.

2.2.3. Isolation of Abyssinone V-4'Methyl Ether. One hundred grams of the obtained extract was subjected to chromatography over silica gel (200-425 mesh particle size) packed in nhexane. Gradient elution was done using n-hexane, hexaneethyl acetate, and ethyl acetate-methanol in increasing polarity (hex 100\%, hex-ethyl acetate: 90-10, 80-20, 70-30, 50-50, 30-70, 20-80, ethyl acetate $100 \%$; ethyl acetate-MeOH: 90-10, $80-20,70-30,50-50,30-70,20-80$, and $\mathrm{MeOH} 100 \%$ ) to give 7 series of fractions mixed base on their TLC profile. Repeated column chromatography with hexane-ethyl acetate (90:10) yielded to $\mathrm{YG}_{4}$ and other compounds. The structures have been elucidated using spectral methods (MS, NMR, and element analysis). The compound $\mathrm{YG}_{4}$ was obtained as a white powder $(500 \mathrm{mg})$ and showed a $[\mathrm{M}]^{+}$at $\mathrm{m} / \mathrm{z}$ 422.2094 corresponding to molecular formula $\left(\mathrm{C}_{26} \mathrm{H}_{30} \mathrm{O}_{5}\right)$. This compound was identified as Abyssinone V-4' methyl ether (Table 1). The presence of a flavanone skeleton was evident from the ${ }^{1}$ HNMR spectra at $\delta 5.27(1 \mathrm{H}$. br), $2.68(1 \mathrm{H}$, dd, $J=2.8$ and $17.2 \mathrm{~Hz})$ and $\delta 3.06(1 \mathrm{H}$. dd. $J=13.2$ and 17.2) corresponding to the $\mathrm{H}-2$ and $\mathrm{H}-3$ protons of the C-ring 
of flavanones, respectively. From the ${ }^{13}$ CNMR spectra, the presence of signal at 79.3 and 42.5 , respectively, indicated the $\mathrm{C}-2$ and $\mathrm{C}-3$ of the $\mathrm{C}$ - ring of flavanones. The ${ }^{1} \mathrm{H}$ and ${ }^{13} \mathrm{CNMR}$ spectra data of this compound were compared to those of the same compound previously isolated [14].

\subsection{In Vitro Experiment}

2.3.1. Cell and Cell Culture. The following cancer cell lines, MCF-7 (human ER-positive breast adenocarcinoma cells), HepG2 (human liver hepatocellular carcinoma), and DU145 and PC3 (human androgens independent prostate carcinoma) cells, were acquired from LGC Promochem (Wesel, Germany).

Culture of HepG2 cells was done using Dulbecco's Modified Eagle Medium (DMEM) supplemented with 10\% of fetal bovine serum (FBS). RPMI 1640 medium supplemented with $10 \%$ fetal bovine serum (FBS) was used for the growth and subculture of MCF-7, DU145, and PC3 cells. All cell cultures were also supplemented with penicillin $100 \mathrm{U} / \mathrm{mL}$, streptomycin $100 \mu \mathrm{g} / \mathrm{mL}$, and HEPES $10 \mathrm{mM}$. The cell cultures were maintained at $37^{\circ} \mathrm{C}$ in a $\mathrm{CO}_{2} 5 \%$ humidified atmosphere and $\mathrm{pH}$ 7.4. After every other day, $90 \%$ of the supernatant was replaced with fresh medium during the cells passage. The number of viable cells was assessed using the trypan blue method and Neubauer chamber was used to assess the number of viable cells and cell count, respectively, prior to performing all experiments.

2.3.2. Treatment of Cells in Culture with Abyssinone V-4' Methyl Ether. Abyssinone V-4' methyl ether (AVME) was freshly dissolved in DMSO and tested in final concentrations ranging from 0.5 to $20 \mu \mathrm{M}$. Controls remained untreated. In all in vitro experiments, treated tumor cell cultures were compared to nontreated control cultures of the same passage and cell numbers per well.

2.3.3. Tumor Cell Growth. The 3-(4,5-dimethylthiazol-2-yl)2,5-diphenyltetrazolium bromide (MTT) dye reduction assay was used to assess cell growth. Treated versus nontreated tumor cells $\left(100 \mu \mathrm{l}, 1 \times 10^{4}\right.$ cells $\left./ \mathrm{ml}\right)$ were seeded onto 96-well tissue culture plates. After 24,48 , and $72 \mathrm{~h}$, MTT $(0.5 \mathrm{mg} / \mathrm{ml})$ was added for an additional $4 \mathrm{~h}$. Thereafter, cells were lysed in a buffer containing $10 \%$ SDS in $0.01 \mathrm{M} \mathrm{HCl}$. The plates were incubated overnight at $37^{\circ} \mathrm{C}, 5 \% \mathrm{CO}_{2}$. Absorbance at $570 \mathrm{~nm}$ was determined for each well using a microplate enzyme-linked immunosorbent assay (ELISA) reader. Each experiment was done in triplicate and repeated 3 times. Results are expressed as mean cell number after subtracting background absorbance, and results are expressed as mean cell number.

\subsection{In Vivo Experiment}

2.4.1. Animals. Experimental female Swiss mice, aged 25-31 days (7-10 g) used in this study, were obtained from the breeding facility of the Laboratory of Biochemistry, University of Yaounde I (Cameroon). Animals were housed in plastic cages at room temperature. They had free access to water and a standard soy-free mouse diet with the following composition: corn $(36.7 \%)$, bone flour (14.5\%), wheat (36.6\%), fish flour (4.8\%), crushed palm kernel (7.3\%), sodium chloride $(0.3 \%)$, and vitamin complex (Olivitazol $\left.{ }^{\circledR}{ }_{-} 0.01 \%\right)$.

2.4.2. Ethical Consideration. The Cameroon Institutional National Ethic Committee approved the housing of animals and all experiments. This committee adopted all procedures recommended by the European Union on the protection of animals used for scientific purposes (CEE Council 86/ 609; Reg. no. FWA-IRD 0001954).

2.4.3. DMBA-Induced Breast Tumor in Mice. Eighteen (18) mice were acclimatized for 20 days and randomly assigned at age of 45-51 days into 3 groups of 6 animals in each. The breast tumor was induced on the $1^{\text {st }}$ day of experiment by a single dose of DMBA (100 mg/kg, per os) dissolved in $1 \mathrm{ml}$ of olive oil to all the experimental groups (12 mice) except control group that received olive oil only. They received the following treatment schedule: the groups control (normal mice) and DMBA (negative control) received distilled water as vehicle. The last group was treated with AVME at the dose of $10 \mathrm{mg} / \mathrm{kg}$. Fifty-six days after the administration of DMBA, all treatments were administered i.p. once daily at about 11:00 A.M. and continued in the same way until 28 days. Every week, experimental mice were weighed and palpated twice a week to check the development of mammary tumors from the first day of acclimatization until the end of the experiment. Tumorous latency (time of tumor appearance) was recorded. All animals that died during the experiment or those that became moribund were sacrificed and autopsy was carried out. At the end of the first month of treatment, all survivors were sacrificed after a $12 \mathrm{~h}$ overnight nonhydric fasting. Two blood samples were collected for each animal: one in an anticoagulant (EDTA) tube for hematological analysis and the other in a dry tube and centrifuged at $600 \times \mathrm{g}$ for $15 \mathrm{~min}$ at $4^{\circ} \mathrm{C}$ for biochemical analysis. The skin was also dissected out to expose mammary tumors and all tumors were removed, counted, and weighed. The size of tumors was measured using a $1 \mathrm{~mm}$ precisions sliding caliper (IGAGING ${ }^{\circledR}$ ). Afterward, the tumorous incidence of different groups was recorded and the formula from Faustino-Rocha et al. [15] (length $\times$ weight $\times$ height $\times \pi / 6$ ) was used to calculate the tumor volume. Estrogen target organs were also removed and weighed. All these organs were fixed in $10 \%$ neutral formalin solution for histomorphology.

2.5. Histological Analysis. Mammary glands, uterus, and vagina were dehydrated by a series of ethanol solution and embedded in paraffin blocks. Microtomy resulted in $5 \mu \mathrm{m}$ sections which were stained with hematoxylin and eosin. An Axioskop 40 microscope connected to a computer was used to determine histomorphological changes. The image was transferred using MRGrab1.0 and Axio Vision 3.1 software (Zeiss Hallbermoos, Germany). Atlas and histologic classification of tumors of rat mammary gland from Russo and Russo [16] aided in this study. 

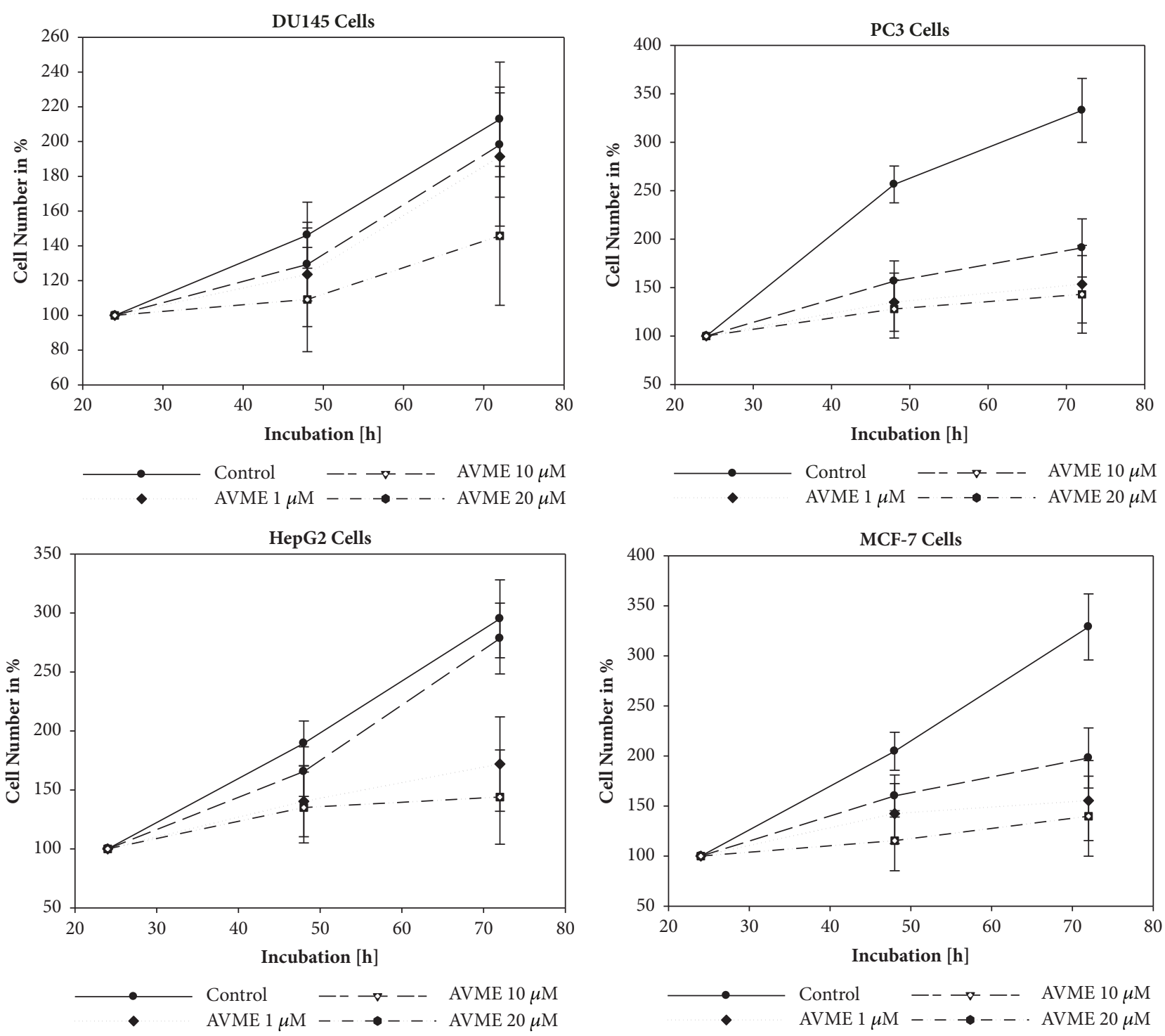

Figure 1: Growth of DU145, PC3, HepG2, and MCF-7 carcinoma cells treated with different concentrations of Abyssinone V-4' methyl ether (AVME) after 24, 48, and 72 hours. Controls remained untreated $(\mathrm{n}=3)$.

2.6. Biochemical and Hematological Analysis. Regarding biochemical analysis, the liver enzyme aspartate transaminase (AST) activity and creatinine level were measured using reagent kits from Fortress Diagnostics Limited (Muckamore, United Kingdom).

Different hematological parameters were also evaluated using a MINDRAY BC-2800 Auto Hematology Analyzer from Shenzhen Mindray Bop-Medical Electronics Co., Ltd. These are white blood cell (WBC) count, lymphocytes, monocytes, granulocytes, red blood cell (RBC) count, and platelets.

2.7. Statistical Analysis. Results are presented as means \pm standard deviation (SD) for each experimental group. Statistical analysis of data with Sigma plot software version 11.00 was realised using the one-way analysis of variance (ANOVA) followed by Dunnett's post hoc test for multiple comparisons.
Statistical significance of differences was considered at a $\mathrm{p}$ value $<0.05$.

\section{Results}

3.1. Tumor Cell Growth. Abyssinone V-4' methyl ether (AVME) showed a concentration-dependent inhibition of DU145, PC3, HepG2, and MCF-7 cells growth. It was also observed that the degree of cytotoxic activity increased time dependently. However, Figure 1 shows only the results for AVME at optimum concentrations. The most significant activity was observed at the final concentrations of 10 and 20 $\mu \mathrm{M}$ in all tested cells.

3.2. Effects on Body Weight. The effects of Abyssinone V4' methyl ether (AVME) were evaluated after 4 weeks of treatment on body weight (Figure 2). It can be observed that 
TABLE 2: Breast cancer chemopreventive activity of Abyssinone V-4' methyl ether after 28 days of treatment.

\begin{tabular}{|c|c|c|c|}
\hline Items & Control & DMBA & DMBA + AVME 10 \\
\hline Number of mice with tumours/total rats & $0 / 6$ & $3 / 5$ & $1 / 5$ \\
\hline Localized tumor incidence (\%) & 0 & $60^{\# \# \#}$ & $20 * * *$ \\
\hline Average tumor weight $(\mathrm{g} / \mathrm{kg})$ & - & $1.04 \pm 03.4$ & $0.48 \pm 0.92 * * *$ \\
\hline$\%$ Inhibition related to tumor weight & - & - & 53.84 \\
\hline Total tumor burden $(\mathrm{g})$ & 0 & 3.92 & 1.67 \\
\hline$\%$ Inhibition related to tumor burden & - & - & 57.39 \\
\hline Volume $\left(\mathrm{cm}^{3}\right)$ & - & $15.32 \pm 3.01$ & $6.8 \pm 0.5 * *$ \\
\hline
\end{tabular}

$\mathrm{NOR}=$ normal mice treated with distilled water; DMBA = negative control treated with water; DMBA + AVME 10 = animals treated with the Abyssinone V-4' methyl etherat the dose of $10 \mathrm{mg} / \mathrm{kg}$. All groups except the normal group (control) received an intragastric dose of DMBA at the dose of $100 \mathrm{mg} / \mathrm{kg}$. Data are represented as mean $\pm \mathrm{SD}(\mathrm{n}=5) . * * \mathrm{p}<0.01$ and $* * * \mathrm{p}<0.001$ as compared to negative control; ${ }^{\# \#} \mathrm{p}<0.001$ as compared to normal group.

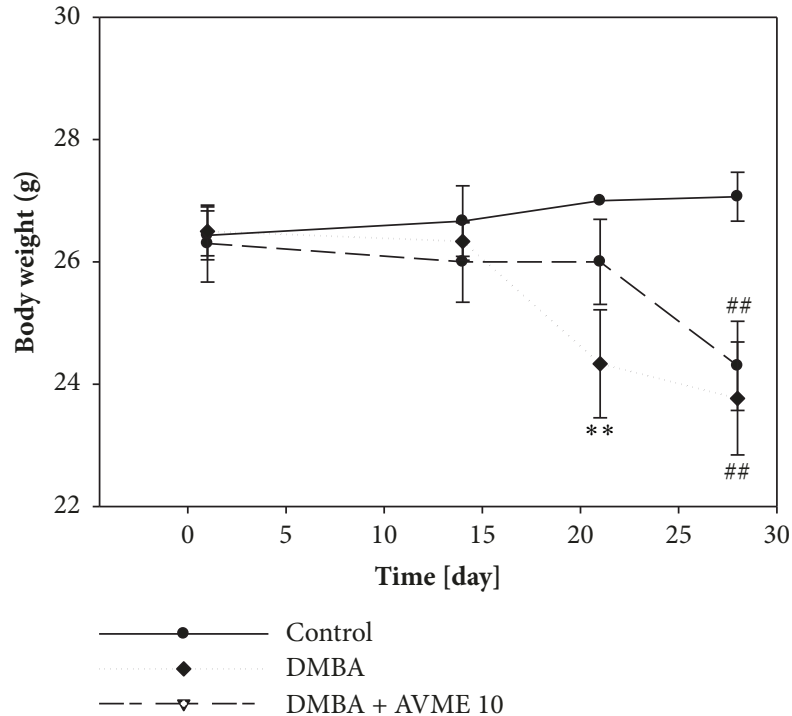

FIGURE 2: Body weight evolution after 4 weeks of treatment. Control $=$ normal mice treated with distilled water; $\mathrm{DMBA}=$ negative control treated with distilled water; DMBA + AVME $10=$ animals treated with the Abyssinone V-4' methyl ether at the dose of 10 $\mathrm{mg} / \mathrm{kg}$. All groups excepting the normal group (control) received an intragastric dose of DMBA at the dose of $100 \mathrm{mg} / \mathrm{kg}$. Data are represented as mean $\pm \mathrm{SD}(\mathrm{n}=5) . * * \mathrm{p}<0.01$ as compared to negative control (DMBA); ${ }^{\# \#} \mathrm{p}<0.01$ as compared to normal group.

the growth of all normal mice was continuous throughout the treatment. However, from the $20^{\text {th }}$ day until the end of the experiment, a significant $(\mathrm{p}<0.01)$ decrease of the body weight in DMBA mice and those treated with AVME (10) was observed. Animals treated with AVME presented a significant ( $\mathrm{p}<0.01)$ lower body weight as compared to the DMBA control group at the $21^{\text {th }}$ day.

3.3. Effects on Mammary Tumors. Table 2 presents data related to chemopreventive activity of Abyssinone V-4' methyl ether (AVME) on mammary glands alteration after 28 days of treatment. No palpable tumor was observed among all the groups 3 months after DMBA $(100 \mathrm{mg} / \mathrm{kg})$ exposition. However, the animals from the normal group presented no localized tumor, while the animals of the DMBA group presented $60 \%$ of localized mammary tumors (noodles). Animals treated with AVME at the dose of $10 \mathrm{mg} / \mathrm{kg}$ showed a significant $(\mathrm{p}<0.001)$ reduction in tumor incidence $(20 \%)$, tumor volume $\left(6.8 \pm 0.5 \mathrm{~cm}^{3}\right.$ versus $15.32 \pm 3.01 \mathrm{~cm}^{3}$ in DMBA group), and an inhibition related to the average tumor weight of $53.84 \%$ as compared to DMBA animals.

3.4. Histomorphological Analysis of Estrogen Target Organs. The mammary gland microarchitectures of mice belonging to the normal group showed normal acini surrounded by a small amount of fibrous conjunctive tissue (Figure 3(a)). Mice that received only DMBA presented mammary gland carcinoma, evidenced by a diminution of the conjunctive tissue as well as a severe hyperplasia of mammary lobules and dilated ducts filled with tumoral cells. Further, in animals treated with AVME $(10 \mathrm{mg} / \mathrm{kg})$, a quasi-normal histoarchitecture of mammary glands with low cellular proliferation and low ductal dilation was observed. A nonsignificant increase of uterine epithelial height was observed in animal that received DMBA (Figures 3(b) and 3(c)).

Moreover, a significant $(\mathrm{p}<0.001)$ increase in the vaginal epithelial height was observed with the mice that received DMBA (Figure 4).

3.5. Effects of Abyssinone V-4' Methyl Ether on Relative Wet Weight of Organs. The relative weights of various organs following 28 days of treatment with Abyssinone V-4' methyl ether are depicted on Table 3. Between the normal and DMBA treated groups, no significant difference in the weight of various organs was observed, except for uterine wet weight that increases $(\mathrm{p}<0.01)$ and spleen wet weight that decreases $(\mathrm{p}<$ 0.05 ), respectively. No significant change was found between DMBA control mice and AVME 10 treated mice in all assessed organ wet weights.

3.6. Effects on Some Biochemical and Hematological Parameters. Table 4 depicts the effects of Abyssinone V-4' methyl ether on some biochemical and hematological parameters. Mice that received only DMBA presented a significant increase in the AST activity $(\mathrm{p}<0.05)$, creatinine $(\mathrm{p}<0.05)$, granulocyte $(\mathrm{p}<0.05)$, and platelets $(\mathrm{p}<0.01)$ levels, while a significant $(\mathrm{p}<0.01)$ decrease of hemoglobin level was found as compared to normal mice (Control). AVME at the dose of $10 \mathrm{mg} / \mathrm{kg}$ showed a significant decrease in the AST activity 

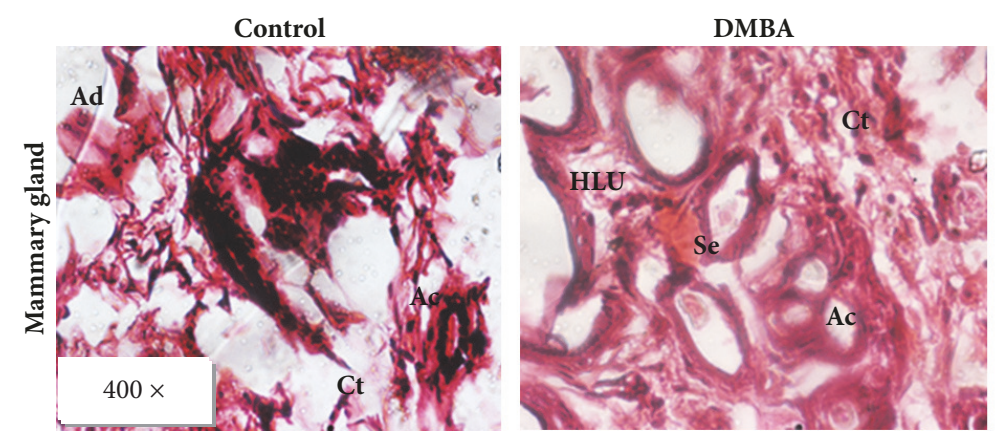

(a)
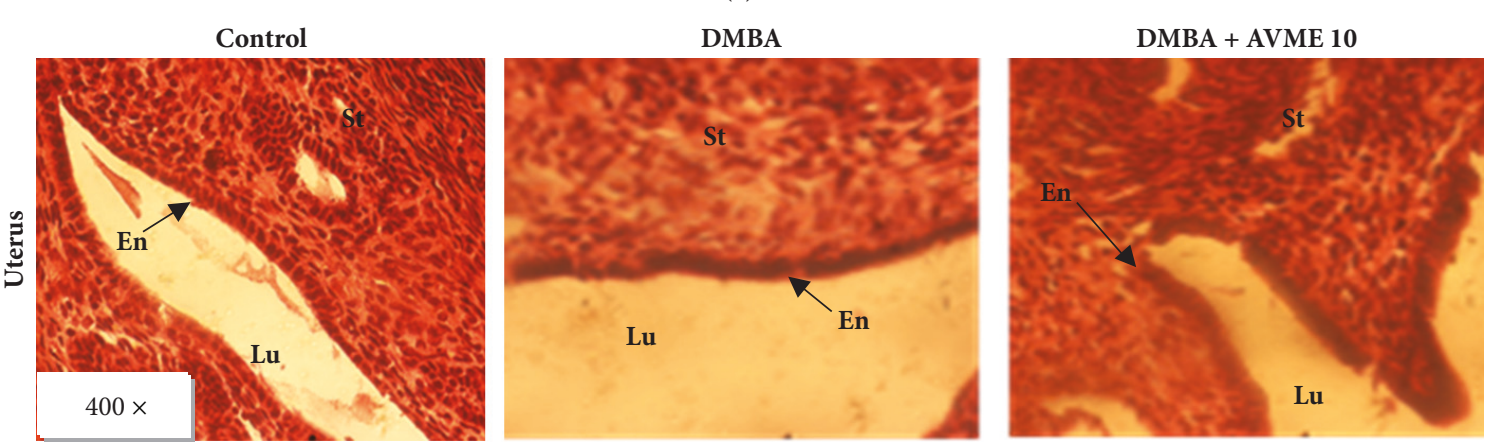

(b)

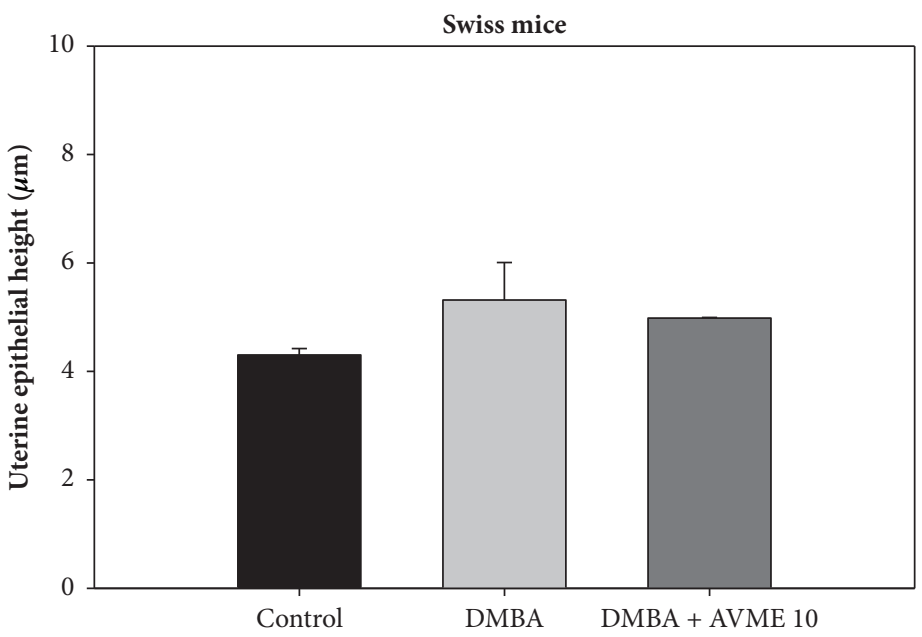

(c)

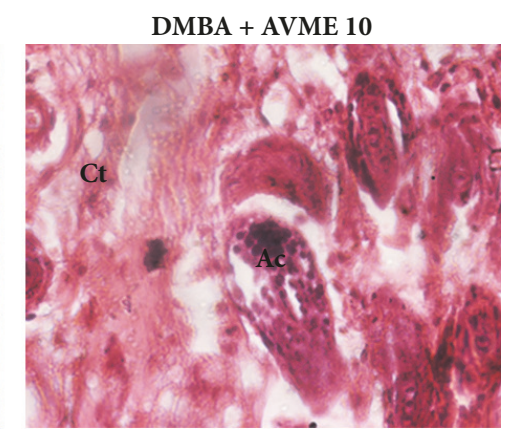

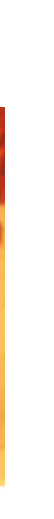


TABLE 3: Effects of Abyssinone V-4' methyl etheron relative wet weights of various organs following 28 days of treatments.

\begin{tabular}{lccc}
\hline Organs & Control & DMBA & DMBA + AVME 10 \\
\hline Uterus & $1539.63 \pm 372.67$ & $2048.19 \pm 184.88 \# \#$ & $2165.28 \pm 180.21 \# \#$ \\
Liver & $40621.32 \pm 951.37$ & $36907.63 \pm 373.71$ & $44855.91 \pm 490.77$ \\
Lungs & $8426.95 \pm 422.95$ & $10602.41 \pm 888.25$ & $12583.0 \pm 812.51$ \\
Spleen & $4322.87 \pm 201.90$ & $2851.40 \pm 380.63 \#$ & $3420.04 \pm 609.28 \# \#$ \\
Adrenals & $675.79 \pm 76.03$ & $441.76 \pm 69.19$ & $571.00 \pm 90.5$ \\
Kidneys & $10004.61 \pm 801.91$ & $11405.62 \pm 714.75$ & $11153.19 \pm 643.13$ \\
Femur & $2572.63 \pm 553.63$ & $2428.19 \pm 81.83$ & $2669.94 \pm 124.11$ \\
Brain & $2580.84 \pm 111.1$ & $3052.21 \pm 171.22$ & $2535.22 \pm 127.81$ \\
Ovaries & $408.40 \pm 70.44$ & $321.28 \pm 71.22$ & $546.60 \pm 67.50$ \\
\hline
\end{tabular}

Control = normal mice treated with distilled water; $\mathrm{DMBA}=$ negative control treated with distilled water; DMBA + AVME $10=$ animals treated with the Abyssinone V-4' methyl etherat the dose of $10 \mathrm{mg} / \mathrm{kg}$. All groups except the normal group (control) received an intragastric dose of DMBA at the dose of 100 $\mathrm{mg} / \mathrm{kg}$. Data are represented as mean $\pm \mathrm{SD}(\mathrm{n}=5) .{ }^{\#} \mathrm{p}<0.05$ and ${ }^{\# \#} \mathrm{p}<0.01$ as compared to normal group.
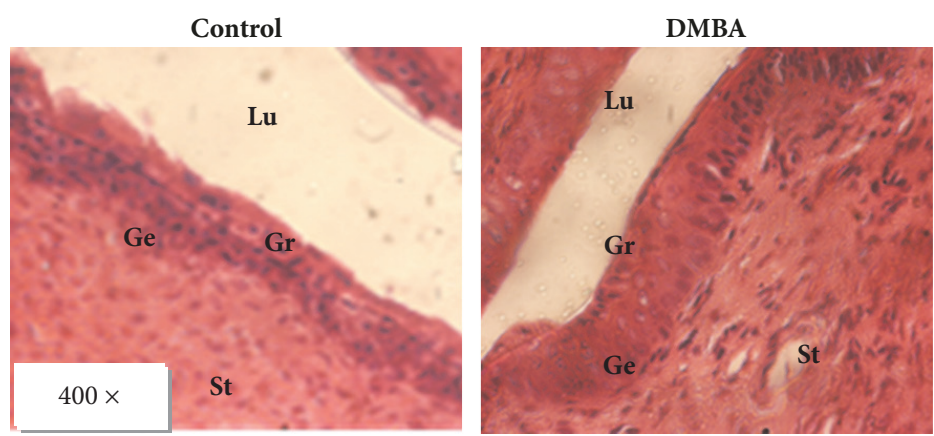

(a)

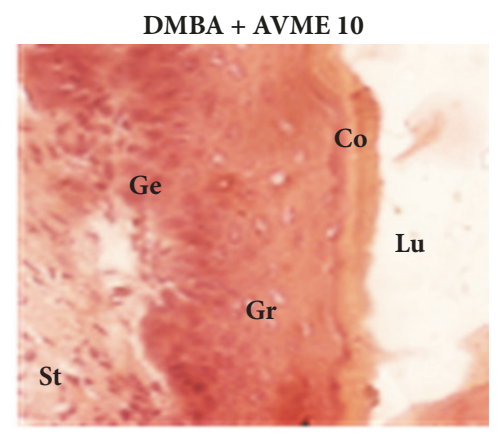

Swiss mice

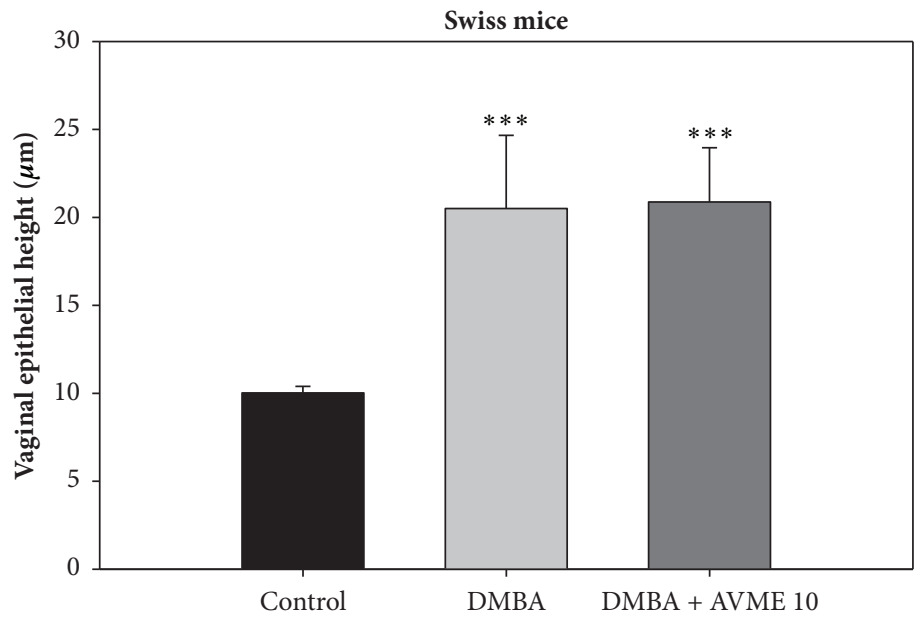

(b)

Figure 4: Effects of Abyssinone V-4' methyl ether on microphotographs H\&E 400× of vagina (a) and graphic representation of vagina epithelial height (b) after 28 days of treatment. Control = normal mice treated with distilled water; DMBA = negative control treated with water; DMBA + AVME $10=$ animals treated with the Abyssinone V-4' methyl ether at the dose of $10 \mathrm{mg} / \mathrm{kg}$. All groups except the normal group (control) received an intragastric dose of DMBA at the dose of $100 \mathrm{mg} / \mathrm{kg}$. Data are represented as mean $\pm \mathrm{SD}(\mathrm{n}=5)$. $* * * \mathrm{p}<0.001$ as compared to negative control. $\mathrm{St}=$ stroma, $\mathrm{Co}=$ stratum corneum, $\mathrm{Gr}=$ stratum granulosum, $\mathrm{Lu}=$ lumen of vagina, and $\mathrm{Ge}=$ stratum germinativum.

toxic and have presented effective results [11]. To contribute to the quest for safer anticancer molecules the in vitro and in vivo antiproliferative properties of Abyssinone V-4' methyl ether isolated from Erythrina droogmansiana (Leguminosae) were explored. Regarding our in vitro antitumoral assays, one of our most important results shows that AVME has antiproliferative effects in all tested cell lines at the optimal concentration of $20 \mu \mathrm{M}$. Of note, the MTT assay measures the ability of a test substance to cause cell death by alteration of one or more cellular functions through the evaluation of 
TABLE 4: Effects of Abyssinone V-4' methyl etheron some biochemical and hematological parameters following 28 days of treatment.

\begin{tabular}{lccc}
\hline Item & Control & DMBA & DMBA + AVME 10 \\
\hline Biochemical parameters & & & $28.6 \pm 1.78 *$ \\
AST & $37.2 \pm 1.26$ & $42.6 \pm 2.13^{\#}$ & $0.36 \pm 0.08 * *$ \\
Creatinine $(\mathrm{g} / \mathrm{L})$ & $0.8 \pm 0.06$ & $1.3 \pm 0.10^{\#}$ & $8.7 \pm 0.72$ \\
\hline Hematological parameters & & & $64.5 \pm 5.69$ \\
WBC $\left(\times 10^{3} \mu \mathrm{L}^{-1}\right)$ & $7.42 \pm 2.67$ & $7.4 \pm 2.48$ & $12.67 \pm 2.08$ \\
Lymphocytes $(\%)$ & $61.1 \pm 4.32$ & $57.11 \pm 4.91$ & $23.23 \pm 4.28 *$ \\
Monocytes $(\%)$ & $11.4 \pm 3.3$ & $11.2 \pm 0.04$ & $151.66 \pm 16.17$ \\
Granulocytes $(\%)$ & $25.1 \pm 5.5$ & $32.1 \pm 4.59^{\#}$ & $9.13 \pm 1.08$ \\
Hemoglobin & $171.1 \pm 6.99$ & $138.2 \pm 9.35^{\# \#}$ & $8.48 \pm 0.35$ \\
RBC $\left(\times 10^{3} \mu \mathrm{L}^{-1}\right)$ & $9.2 \pm 0.051$ & $959.2 \pm 11.07^{\# \#}$ & $83.33 \pm 294.65^{\# \#}$ \\
Platelets $\left(\times 10^{3} \mu \mathrm{L}^{-1}\right)$ & $453 \pm 10.42$ & & \\
\hline
\end{tabular}

Control $=$ normal mice treated with distilled water; $\mathrm{DMBA}=$ negative control treated with distilled water; DMBA + AVME $10=$ animals treated with the Abyssinone V-4' methyl etherat the dose of $10 \mathrm{mg} / \mathrm{kg}$. All groups except the normal group (control) received an intragastric dose of DMBA at the dose of 100 $\mathrm{mg} / \mathrm{kg}$. Data are represented as mean $\pm \mathrm{SD}(\mathrm{n}=5) . * \mathrm{p}<0.05 . * * \mathrm{p}<0.01$ as compared to negative control; ${ }^{\#} \mathrm{p}<0.05$ and ${ }^{\# \#} \mathrm{p}<0.01$ as compared to normal group.

cell proteins production [18]. These effects suggest that AVME is endowed with anticancer properties and corroborate many studies which described flavonols as cytotoxic in vitro $[19,20]$.

For in vivo experiment, the protective effects of AVME on 7,12-dimethylbenz(a)anthracene- (DMBA-) induced breast tumors in mice were assessed. DMBA is a polycyclic aromatic hydrocarbon well-known potent environmental carcinogen which has been used to induce carcinogenesis in the mammary gland or skin of experimental rodents such as rat and mouse $[16,21]$. In this study, DMBA was administered at a single dose of $100 \mathrm{mg} / \mathrm{kg}$ BW by intragastric gavage to Swiss mice aged between 45 and 50 days to induce mammary tumors. Due to the active proliferation of the terminal ducts in breast tissue for rodents in this range of age, they become very susceptible to carcinogens and tumor development [22]. Experimental animals that received only DMBA developed large tumors after 12 weeks of study, whereas normal animals did not exhibit tumors. This result is in agreement with studies of Minari and Okeke [23] that found similar results with DMBA in female Swiss mice after 6 weeks. The significant reduction in tumor volume and average tumor weight observed with AVME at the dose of $10 \mathrm{mg} / \mathrm{kg}$ suggest a protective effect of this compound on the mammary tumorigenesis. These effects could be explained by the ability of AVME to inhibit breast cancer cell growth, as observed in vitro in this study. This is in agreement with the previous studies showing the antiproliferative effects of herbal polyphenols, in various human cancer cell lines [24, 25]. Of note, breast tissue is a well-known target of flavonols, which could explain the observed cancer protective potential of AVME, since they are proapoptotic and are endowed with cell cycle arrest property [26]. Results obtained on histopathological examination of the mammary gland sections are in line with those observed in tumor volume and average tumor weight. In fact, the evidence of DMBAinduced lobular alveolar hyperplasia in the mammary gland histological sections of untreated mice suggests a neoplastic transformation, which is a hallmark of DMBA-induced tumor in rodents $[22,27]$. This result is in accordance with several observations, which showed that DMBA alters the normal process of mammary gland differentiation of terminal ducts to alveoli and lobules $[24,25,28]$. The mice treated with AVME exhibited a quite-normal histological sections as compared to the in situ carcinoma observed in DMBA control animals. This strongly suggests a protective effect of AVME in DMBA-induced cell proliferation in the breast tissue of mice.

Abyssinones are prenylated flavanones existing in plant of the genus Erythrina well known to exhibit diverse biological activities including in vitro anticancer activities [12, 13]. In fact, Samaga et al. [29] showed that Abyssinones I and II triggered apoptosis by upregulation of p53 and Bax, while they downregulated Bcl-2. According to the same authors, Abyssinones I and II induced apoptosis through mitochondrial pathway releasing cytochrome $c$ and Apaf-1 into cytosol, associated with activation of caspase-3. In addition, Kuete et al. [30] demonstrated the antiproliferative potential of Abyssinone IV. This later also induced apoptosis in morphologic variations in human leukemic lymphoblasts (CCRFCEM cells) mediated by the loss of mitochondrial membrane potential (MMP) and increase in ROS production. These observations support the ability of abyssinones to trigger apoptosis via mitochondrial pathway by activation of caspase-3. Obviously, AVME could use similar mechanisms to exhibit its antitumor activities observed in this study.

As far as toxicological status of animals is concerned, relative weight of organs is a good indicator of toxic effects of tested substances [31]. In this study, a significant increase in the uterine wet weight was observed; however endometrium height was unchanged, suggesting that AVME is not a threat for endometrial cancer. In fact, this observation is in accordance with the previous ones, which reported that AVME is endowed with estrogenic/antiestrogenic properties 
in ovariectomized rats $[32,33]$. Furthermore, an increase of the aspartate transaminase activity and creatinine level in DMBA control group was observed. This could be explained by toxic effects of DMBA, which is able to induce hemorrhagic injuries in different organs such as liver and kidney [34]. Nevertheless, AVME prevented the DMBA-induced liver and kidney injuries in mice.

\section{Conclusion}

In summary, Abyssinone V-4' methyl ether inhibits DU145, PC3, HepG2, and MCF-7 cells growth. Furthermore, AVME inhibits the DMBA-induced mammary glands hyperplasia in mice at the dose of $10 \mathrm{mg} / \mathrm{kg}$, evidenced by the decrease of tumor incidence, tumor weight, and volume as well as a protective effect against the lobular alveolar hyperplasia. Taken all together, these results suggest that Abyssinone V-4' methyl ether is endowed with antitumor properties and could be a source of traditional medicine which deserves to be more elucidated and explored in the foreseeable future.

$\begin{array}{ll}\text { Abbreviations } \\ \text { AVME: } & \text { Abyssinone V-4' methyl ether } \\ \text { AST: } & \text { Aspartate transaminase } \\ \text { BW: } & \text { Body weight } \\ \text { CC }_{50}: & \text { Cytotoxic concentration for 50\% of the } \\ & \text { cells } \\ \text { CCRF-CEM: } & \text { Morphologic variations in human } \\ & \text { leukemic lymphoblasts } \\ \text { DMEM: } & \text { Dulbecco's Modified Eagle Medium } \\ \text { DMBA: } & \text { 7,12 dimethylbenz(a)anthracene } \\ \text { DMSO: } & \text { Dimethylsulfoxide } \\ \text { ER: } & \text { Estrogen receptor } \\ \text { FBS: } & \text { Fetal bovine serum } \\ \text { HEPES: } & \text { 4-(2-hydroxyethyl)-1- } \\ & \text { piperazineethanesulfonic } \\ & \text { acid } \\ \text { Hb: } & \text { Hemoglobin } \\ \text { Ht: } & \text { Hematocrit } \\ \text { NHC: } & \text { National Herbarium of Cameroon } \\ \text { RBC: } & \text { Red blood cell } \\ \text { RPMI: } & \text { Roswell Park Memorial Institute medium } \\ \text { SD: } & \text { Standard deviation. }\end{array}$

\section{Data Availability}

The data used to support the findings of this study are included within the article.

\section{Conflicts of Interest}

The authors declare that there are no conflicts of interest regarding the publication of this paper.

\section{Acknowledgments}

The authors would kindly thank Professors Roman A. Blaheta (University Hospital Frankfurt) and Tânia Beatriz
Creczynski-Pasa (Federal University of Santa Catarina) for their collaboration.

\section{References}

[1] C. D. M. Fletcher, J. A. Bridge, S. J. Schnitt, and P. H. Tan, Pathology and Genetics of tumours of the breast, World Health Organization Classification of Tumours, IARC Press, Lyon, 4 edition, 2012.

[2] D. Hanahan and R. A. Weinberg, "Hallmarks of cancer: the next generation," Cell, vol. 144, no. 5, pp. 646-674, 2011.

[3] M. Plummer, C. de Martel, J. Vignat, J. Ferlay, F. Bray, and S. Franceschi, "Global burden of cancers attributable to infections in 2012: a synthetic analysis," The Lancet Global Health, vol. 4, no. 9, pp. e609-e616, 2016.

[4] Cancer Report Worldwide, Crisis of Cancer Impact Worldwide Exposed, Press Release, WCD, 2014.

[5] J. Ferlay, I. Soerjomataram, R. Dikshit et al., "Cancer incidence and mortality worldwide: sources, methods and major patterns in GLOBOCAN 2012," International Journal of Cancer, 2014.

[6] R. Clarke, M. C. Liu, K. B. Bouker et al., "Antiestrogen resistance in breast cancer and the role of estrogen receptor signaling," Oncogene, vol. 22, no. 47, pp. 7316-7339, 2003.

[7] J. J. Jobsen, J. Van Der Palen, M. Brinkhuis, F. Ong, and H. Struikmans, "Sequence of radiotherapy and chemotherapy in breast cancer after breast-conserving surgery," International Journal of Radiation Oncology Biology Physics, vol. 82, no. 5, pp. e811-e817, 2012.

[8] M. O. Palumbo, P. Kavan, W. H. Miller Jr. et al., "Systemic cancer therapy: Achievements and challenges that lie ahead," Frontiers in Pharmacology, vol. 4, 2013.

[9] C.-H. Pui and W. E. Evans, "Treatment of acute lymphoblastic leukemia," The New England Journal of Medicine, vol. 354, no. 2, pp. 166-178, 2006.

[10] T. P. Kingham, O. I. Alatise, V. Vanderpuye et al., "Treatment of cancer in sub-Saharan Africa," The Lancet Oncology, vol. 14, no. 4, pp. e158-e167, 2013.

[11] Y. Wang, J. Wang, H. Wang, and W. Ye, "Novel taxane derivatives from Taxus wallichiana with high anticancer potency on tumor cells," Chemical Biology \& Drug Design, vol. 88, no. 4, pp. 556561, 2016

[12] A. Maiti, M. Cuendet, V. L. Croy, D. C. Endringer, J. M. Pezzuto, and M. Cushman, "Synthesis and biological evaluation of $( \pm)$ abyssinone II and its analogues as aromatase inhibitors for chemoprevention of breast cancer," Journal of Medicinal Chemistry, vol. 50, no. 12, pp. 2799-2806, 2007.

[13] G. V. Rao, B. N. Swamy, V. Chandregowda, and G. C. Reddy, "Synthesis of $( \pm)$ Abyssinone I and related compounds: Their anti-oxidant and cytotoxic activities," European Journal of Medicinal Chemistry, vol. 44, no. 5, pp. 2239-2245, 2009.

[14] A. Yenesew, J. O. Midiwo, M. Miessner, M. Heydenreich, and M. G. Peter, "Two prenylated flavanones from stem bark of Erythrina burttii," Phytochemistry, vol. 48, no. 8, pp. 1439-1443, 1998.

[15] A. Faustino-Rocha, P. A. Oliveira, J. Pinho-Oliveira et al., "Estimation of rat mammary tumor volume using caliper and ultrasonography measurements," Lab Animal, vol. 42, no. 6, pp. 217-224, 2013.

[16] J. Russo and I. H. Russo, "Experimentally induced mammary tumors in rats," Breast Cancer Research and Treatment, vol. 39, no. 1, pp. 7-20, 1996. 
[17] J. D. Ngowa, J. M. Kasia, J. Yomi et al., "Breast Cancer Survival in Cameroon: Analysis of a Cohort of 404 Patients at the Yaoundé General Hospital," Advances in Breast Cancer Research, vol. 04, no. 02, pp. 44-52, 2015.

[18] J. Weyermann, D. Lochmann, and A. Zimmer, "A practical note on the use of cytotoxicity assays," International Journal of Pharmaceutics, vol. 288, no. 2, pp. 369-376, 2005.

[19] E. Espinosa, P. Zamora, J. Feliu, and M. González Barón, "Classification of anticancer drugs - A new system based on therapeutic targets," Cancer Treatment Reviews, vol. 29, no. 6, pp. 515-523, 2003.

[20] M. B. Kastan and J. Bartek, "Cell-cycle checkpoints and cancer," Nature, vol. 432, no. 7015, pp. 316-323, 2004.

[21] D. Saha and M. Hait, "An ontological design: two stage mouse skin carcinogenesis induced by DMBA and promoted by croton oil," Asian Journal of Pharmaceutical Sciences, p. 2, 2012.

[22] E. Rubin and I. Damjanov, "Comparative study of human and rat mammary tumorigenesi," Lab Invest, vol. 5, pp. 187-200, 2000 .

[23] J. B. Minari and U. Okeke, "Chemopreventive effect of Annona muricata on DMBA-induced cell proliferation in the breast tissues of female albino mice," Egyptian Journal of Medical Human Genetics, vol. 15, no. 4, pp. 327-334, 2014.

[24] M. Haghiac and T. Walle, "Quercetin induces necrosis and apoptosis in SCC-9 oral cancer cells," Nutrition and Cancer, vol. 53, no. 2, pp. 220-231, 2005.

[25] K. Bishayee, S. Ghosh, A. Mukherjee, R. Sadhukhan, J. Mondal, and A. R. Khuda-Bukhsh, "Quercetin induces cytochrome-c release and ROS accumulation to promote apoptosis and arrest the cell cycle in G2/M, In cervical carcinoma: Signal cascade and drug-DNA interaction," Cell Proliferation, vol. 46, no. 2, pp. 153-163, 2013.

[26] A. Murakami, H. Ashida, and J. Terao, "Multitargeted cancer prevention by quercetin," Cancer Letters, vol. 269, no. 2, pp. 315$325,2008$.

[27] R. C. Moon, J. C. Grubbs, and M. B. Sporn, "Inhibition of 7,12dimethylbenz(a)anthracene-induced mammary carcinogenesis by retinylacetat," Cancer Research, vol. 36, pp. 2626-2630, 1976.

[28] R. Vidya Priyadarsini, R. Senthil Murugan, S. Maitreyi, K. Ramalingam, D. Karunagaran, and S. Nagini, "The flavonoid quercetin induces cell cycle arrest and mitochondria-mediated apoptosis in human cervical cancer (HeLa) cells through p53 induction and NF- $\kappa$ B inhibition," European Journal of Pharmacology, vol. 649, no. 1-3, pp. 84-91, 2010.

[29] K. K. L. Samaga, G. V. Rao, G. Chandrashekara Reddy, A. K. Kush, and L. Diwakar, "Synthetic racemates of abyssinone i and II induces apoptosis through mitochondrial pathway in human cervix carcinoma cells," Bioorganic Chemistry, vol. 56, pp. 54-61, 2014.

[30] V. Kuete, L. P. Sandjo, D. E. Djeussi et al., "Cytotoxic flavonoids and isoflavonoids from Erythrina sigmoidea towards multifactorial drug resistant cancer cells," Investigational New Drugs, vol. 32, no. 6, pp. 1053-1062, 2014.

[31] B. Michael, B. Yano, R. S. Sellers et al., "Evaluation of organ weights for rodent and non-rodent toxicity studies: a review of regulatory guidelines and a survey of current practices," Toxicologic Pathology, vol. 35, no. 5, pp. 742-750, 2007.

[32] M. A. Mvondo, D. Njamen, S. Tanee Fomum, and J. Wandji, "Effects of alpinumisoflavone and abyssinone V-4/-methyl ether derived from Erythrina lysistemon (Fabaceae) on the genital tract of ovariectomized female Wistar rat," Phytotherapy Research, vol. 26, no. 7, pp. 1029-1036, 2012.
[33] D. Njamen, M. A. Mvondo, T. N. Gueyo, S. Zingue, S. T. Fomum, and J. Wandji, "Erythrina lysistemon-derived flavonoids account only in part for the plant's specific effects on rat uterus and vagina," Journal of Basic and Clinical Physiology and Pharmacology, vol. 26, no. 3, pp. 287-294, 2015.

[34] C. F. Awounfack, S. B. Ateba, S. Zingue, O. R. Mouchili, and D. Njamen, "Safety evaluation (acute and sub-acute studies) of the aqueous extract of the leaves of Myrianthus arboreus P. Beauv. (Cecropiaceae) in Wistar rats," Journal of Ethnopharmacology, vol. 194, pp. 169-178, 2016. 


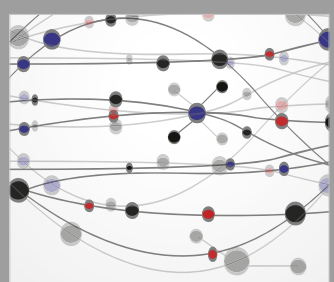

The Scientific World Journal
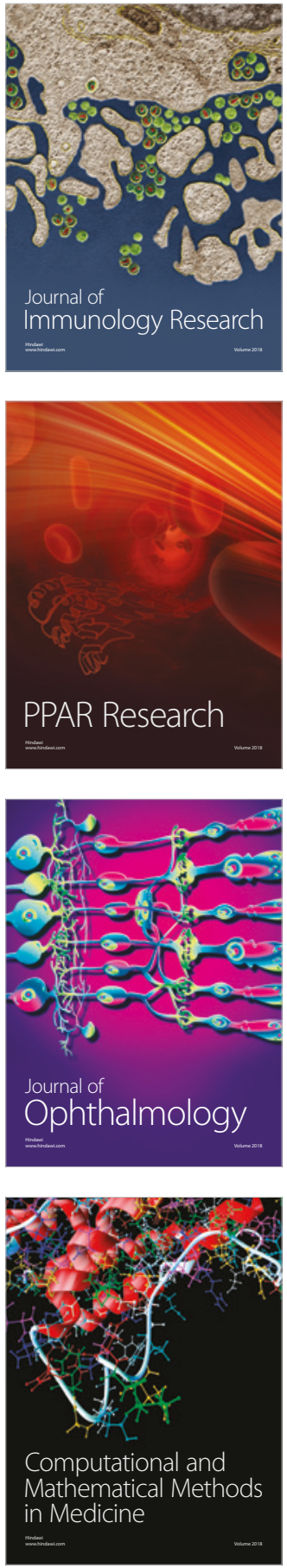

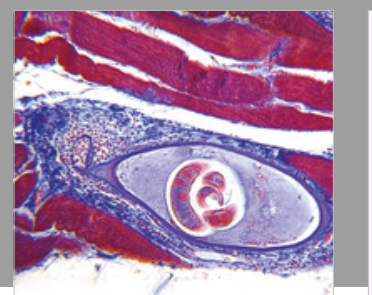

Gastroenterology Research and Practice

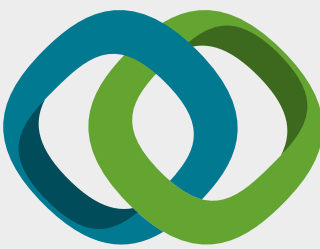

\section{Hindawi}

Submit your manuscripts at

www.hindawi.com
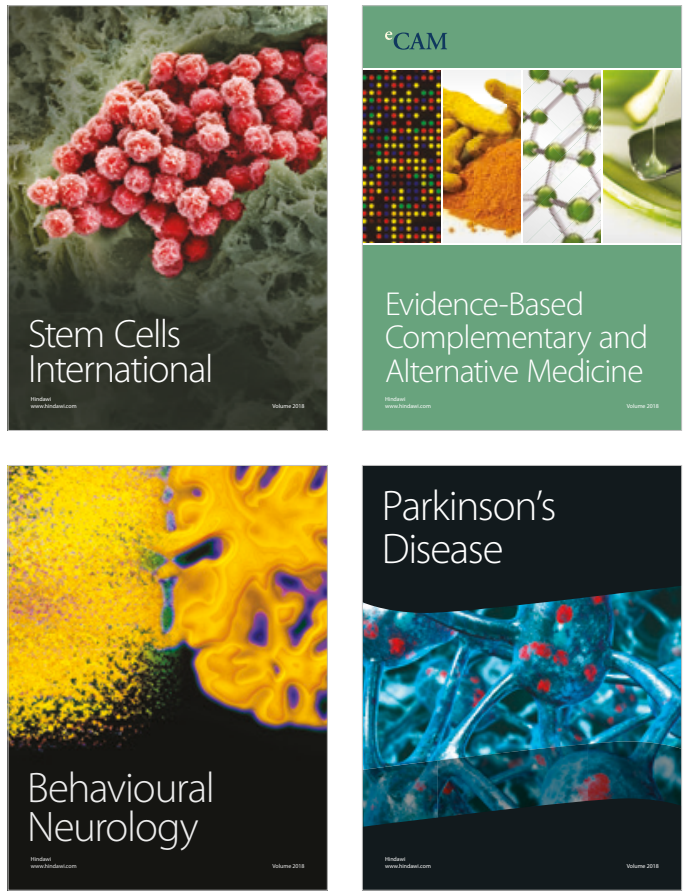

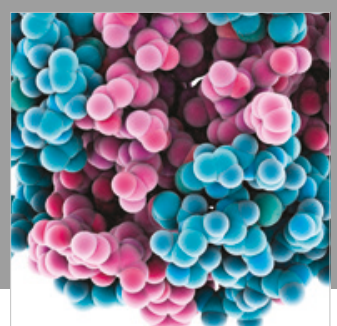

ournal of

Diabetes Research

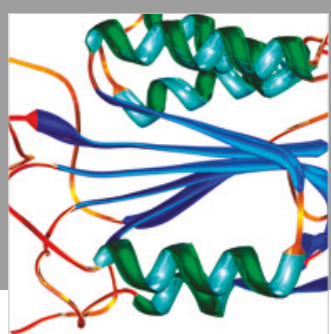

Disease Markers
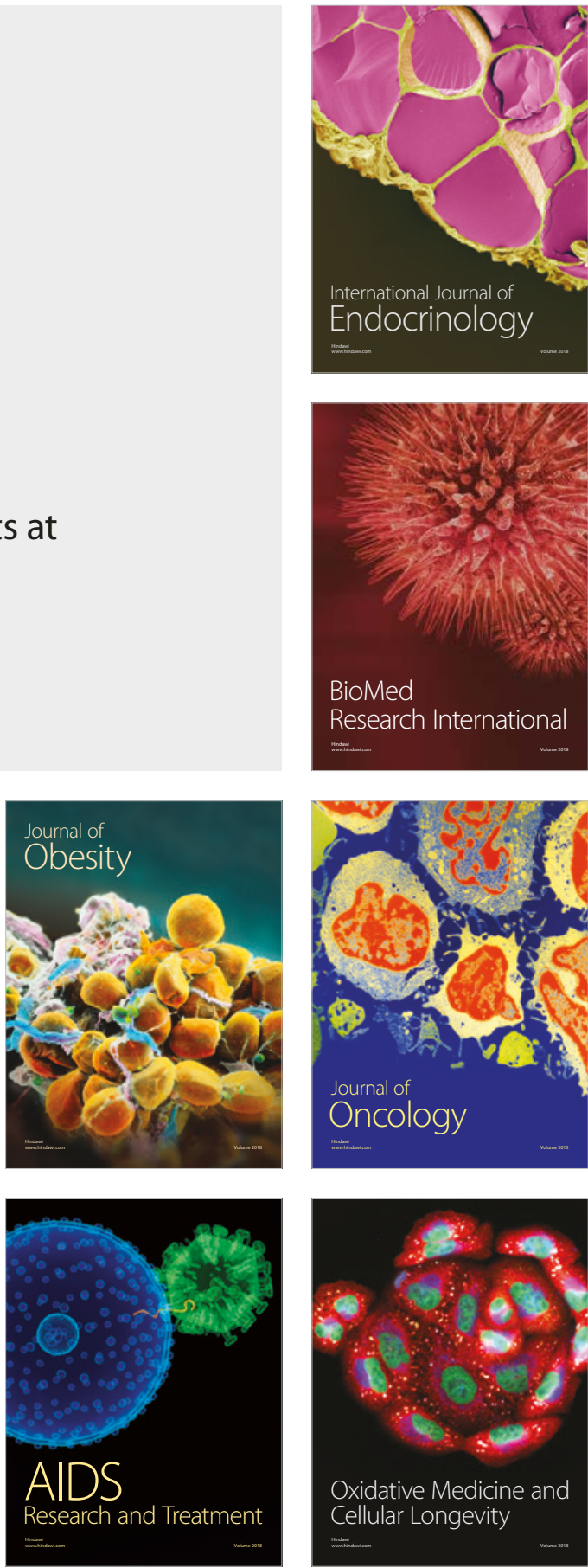